\title{
Bile duct adenoma causing recurrent cholangitis: diagnosis and management with targeted Spyglass access and radiofrequency ablation
}

A 77-year-old man was admitted for evaluation of recurrent episodes of cholangitis. He had undergone endoscopic retrograde cholangiography (ERC) several times for biliary stone disease and for cholecystectomy, and suffered from advanced Alzheimer disease. Abdominal magnetic resonance imaging (MRI) revealed dilatation of the right posterior intrahepatic duct ( Fig.1), with aberrant drainage directly into the common hepatic duct. However, multiple attempts to reach this segment by ERC were unsuccessful ( $\bullet$ Fig.2). The Spyglass system was then used for selective opacification ( Fig.3) and optical viewing of the aberrant bile duct (Boston Scientific, Natick, Massachusetts, USA) [1,2]. A reddish nodular lesion was seen obstructing the lumen ( $\bullet$ Fig.4), and targeted biopsies with a 3-Fr Spybite mini-forceps (Boston Scientific) confirmed the presence of an adenoma ( $\bullet$ Fig.5) [3]. The stricture was dilated with a Hurricane $8-\mathrm{mm}$, 4-cm balloon (Boston Scientific) and the stones were extracted. The Spyscope was removed and two 7-Fr plastic stents placed. Given the patient's poor mental and general status, we proposed carrying out endobiliary radiofrequency ablation of the stricture. This was done 4 weeks later with a wire-guided Habib EndoHPB (Emcision, London, UK) ( Fig. 6) [4]. This case illustrates the potential impact of selective cholangioscopy with the Spyglass system on diagnosis and management of indeterminate biliary strictures.

Endoscopy_UCTN_Code_TTT_1AR_2AF

Competing interests: None

\section{G. Mavrogenis ${ }^{1}$, P. H. Deprez ${ }^{2}$,}

\section{J. Wallon ${ }^{3}$, P. Warzée}

${ }^{1}$ Department of Hepato-gastroenterology, Grand Hôpital de Charleroi, Site Notre Dame, Charleroi, Belgium

${ }^{2}$ Department of Hepato-gastroenterology, Cliniques Universitaires Saint-Luc, Université Catholique de Louvain, Brussels, Belgium

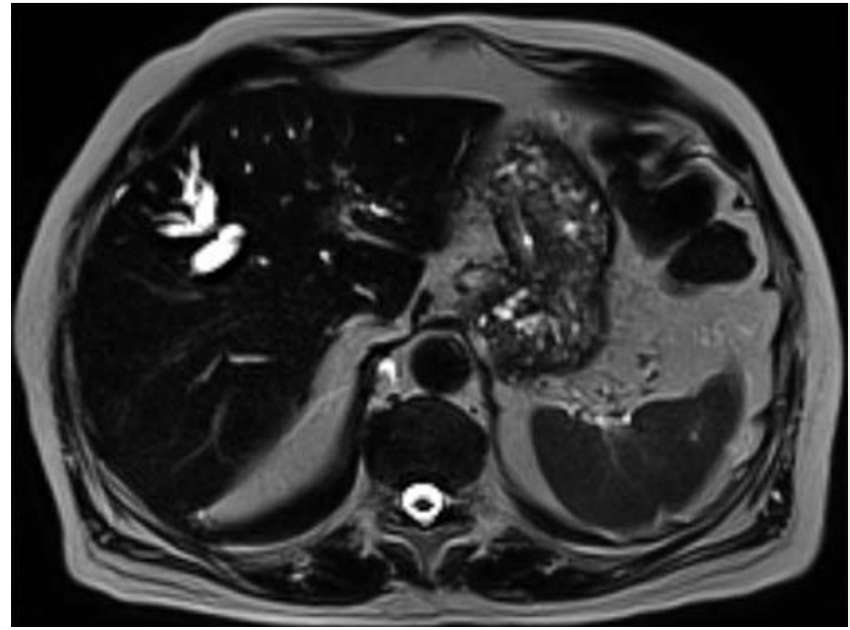

Fig. 1 Magnetic resonance imaging (MRI) showing dilatation of the right posterior hepatic duct, without visible cause of obstruction, in a 77-yearold man with history of recurrent episodes of cholangitis.

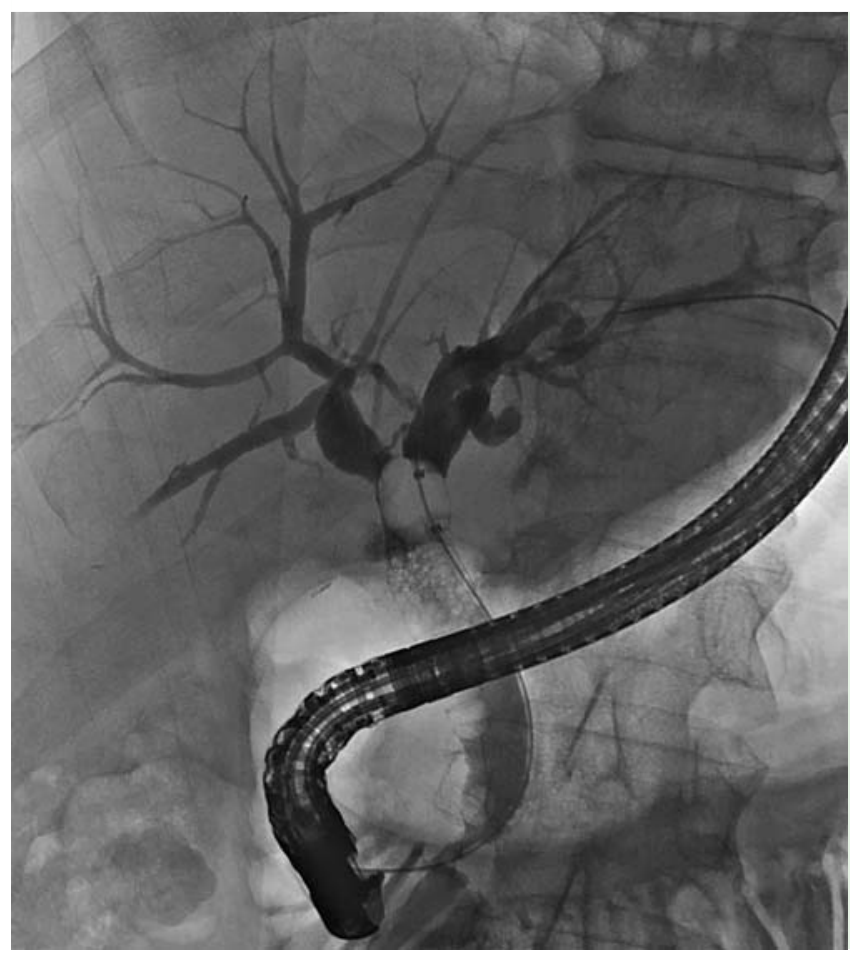

Fig. 2 Failure to opacify the aberrant right hepatic duct with classical filling techniques during endoscopic retrograde cholangiography (ERC). 


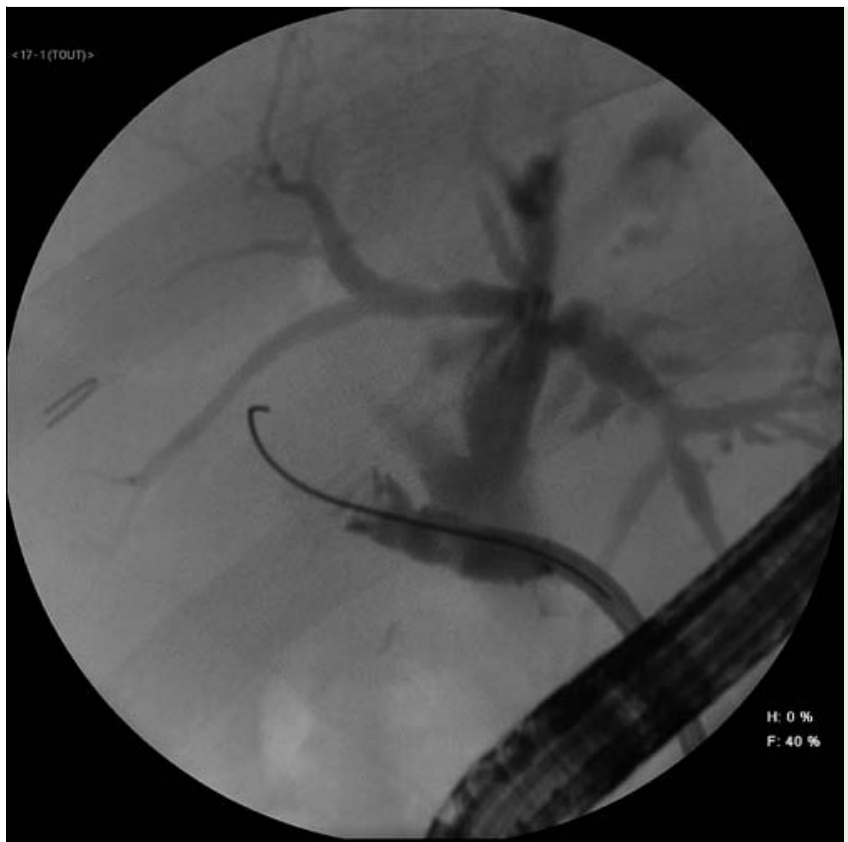

Fig. 3 Targeted access to the aberrant posterior right bile duct with the Spyglass system showing tumoral obstruction.

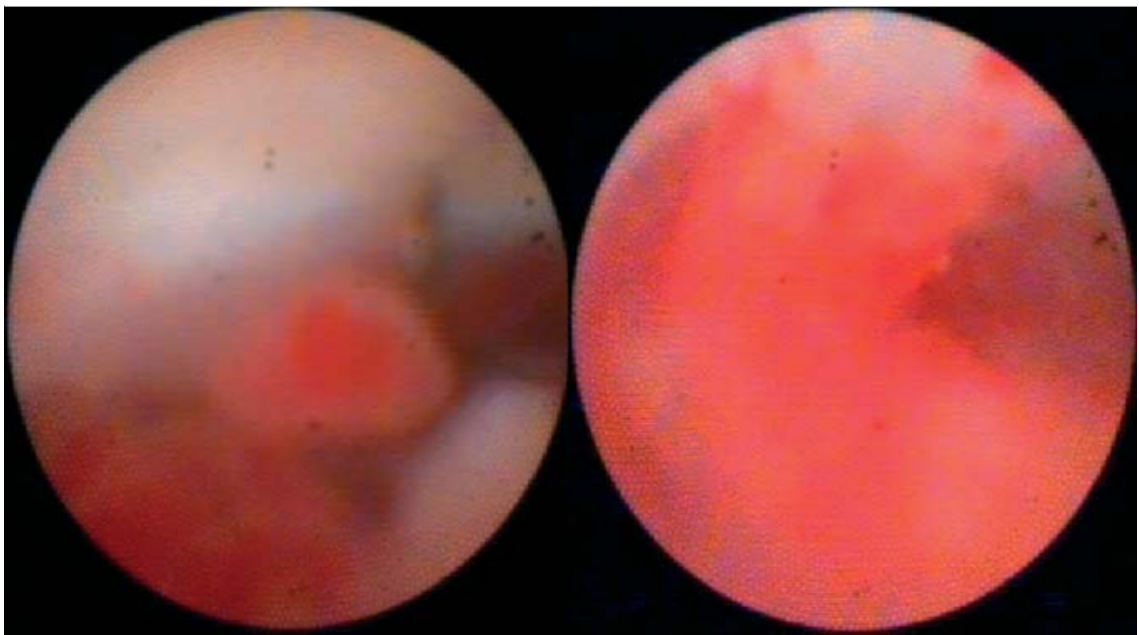

Fig.4 Optical viewing of the aberrant bile duct with the Spyglass system showing a nodular lesion obstructing the lumen.

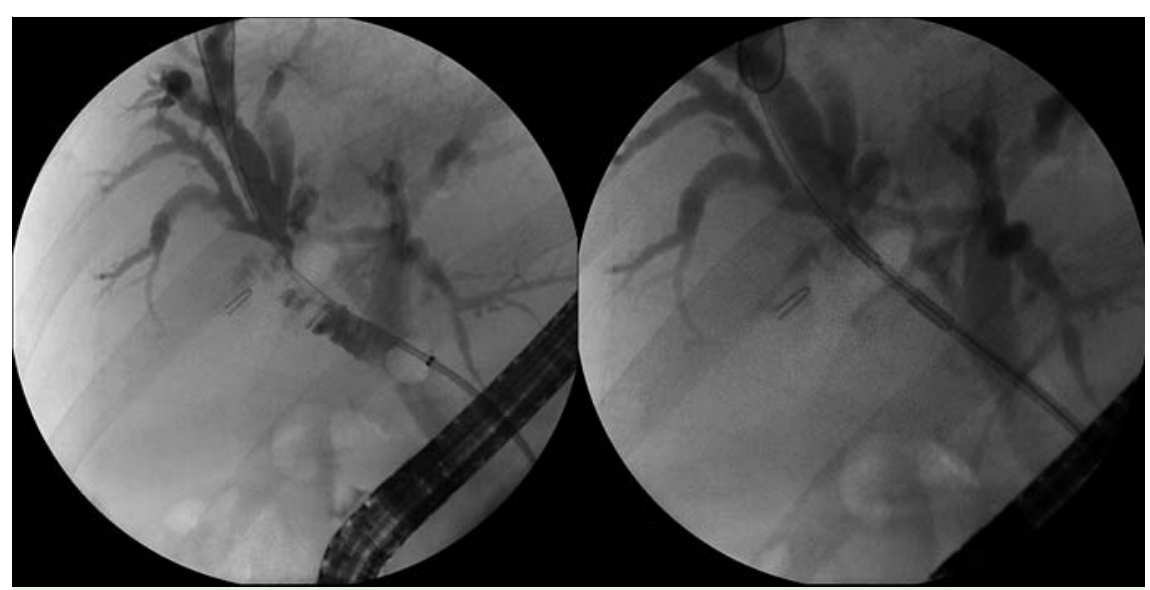

Fig. 6 Guide wire inserted through the biliary stenosis (left) and a Habib EndoHPB catheter placed at the level of the intraductal adenoma (right).

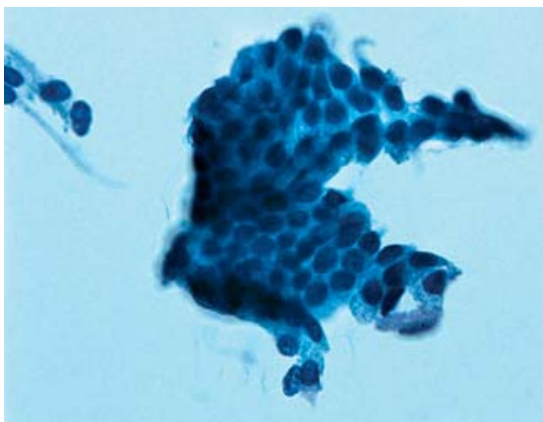

Fig. 5 Histological section of the biliary adenoma, characterized by the regular sheets of monotonous cells, with monomorphic nuclei localized to the bottom of the cytoplasm (Papanicolaou stain; magnification $\times 25$ ).

${ }^{3}$ Department of Pathology, Cliniques Universitaires Saint-Luc, Université Catholique de Louvain, Brussels, Belgium

\section{References}

1 Chen YK. Preclinical characterization of the Spyglass peroral cholangiopancreatoscopysystem for direct access, visualization, and biopsy. Gastrointest Endosc 2007; 65: 303 311

2 Draganov PV, Chauhan S, Wagh MS et al. Diagnostic accuracy of conventional and cholangioscopy-guided sampling of indeterminate biliary lesions at the time of ERCP: a prospective, long-term follow-up study. Gastrointest Endosc 2012; 75: 347-353

3 Rustgi AK, Kelsey PB, Guelrud M et al. Malignant tumors of the bile ducts: diagnosis by biopsy during endoscopic cannulation. Gastrointest Endosc 1989; 35: 248-251

4 Monga A, Gupta R, Ramchandani M et al. Endoscopic radiofrequency ablation of cholangiocarcinoma: new palliative treatment modality (with videos). Gastrointest Endosc 2011; 74: 935 -937

\section{Bibliography}

DOI http://dx.doi.org/

10.1055/s-0032-1310036

Endoscopy 2012; 44: E290-E291

(c) Georg Thieme Verlag KG

Stuttgart · New York

ISSN 0013-726X

\section{Corresponding author}

\section{P. Warzée}

Grand Hôpital de Charleroi

Site Notre Dame

3 Grand Rue

6000 Charlero

Belgium

Fax: +327-1102-779

pwarzee@hotmail.com 